\title{
Hubungan Human, Organisasi, Dan Teknologi Terhadap Kepuasan Penggunaan Aplikasi Primary Care Di Klikik Pratama Kota Pekanbaru
}

\author{
Tri Purnama Sari ${ }^{1}$, Wen Via Trisna ${ }^{2}$, Haryani Octaria ${ }^{3}$, Doni Jepisah $^{4}$ \\ ${ }^{1,2}$ STIKes Hang Tuah Pekanbaru \\ Email: ${ }^{1}$ Tripurnamasari@htp.ac.id \\ 2,3,4Email: ${ }^{2}$ Wenviatrisna@htp.ac.id, Haryanioctaria@htp.ac.id, donijepisah@htp.ac.id
}

\begin{abstract}
Abstrac
Satisfaction of Primary Care application users becomes the need to guarantee the accountability of services to BPJS. To measure the level of satisfaction of the Primary Care application, the End User Computation Satisfaction (EUCS) method is used. The aim of the study was to study the relationship between humans, organizations, and technology with EUCS (End User Satisfaction Computing at Pekanbaru pratama city clinic. This type of research is a quantitative cross sectional study with primary information system networks. Variables used were factor-independent variables HOT ( human) EUCS (End User Computing Satisfaction) The research subjects were primay care information system operators with a sample of 90 pratama clinics in the city of Pekanbaru that were taken as total samples, which stated that humans were quite good about being satisfied with the use of $p$ care as much as $2(100 \%)$, respondents who stated that the organization was good enough about satisfaction with the use of p care, namely as much as 5 (100\%), and respondents who stated that the technology was good enough needed to be satisfied with the use of p care, which was $6(60 \%)$.
\end{abstract}

Keywords: human, organization, technology, EUCS, Klinik pratama

\begin{abstract}
Abstrak
Kepuasan pengguna aplikasi Primary Care menjadi kebutuhan untuk menjamin kinerja pelaporan pelayanan ke BPJS. Untuk mengukur tingkat kepuasan aplikasi Primary Care tersebut, maka digunakanlah metode End-User Computing Satisfaction (EUCS). Tujuan penelitian adalah untuk mengetahui hubungan human, organization, dan tecnologi dengan EUCS (End User Computing Satisfaction di klinik pratama kota pekanbaru. Jenis penelitian adalah penelitian kuantitatif bersifat cross sectional dengan obyek sistem informasi Primary Care. Variabel yang diteliti adalah variabel bebas faktor HOT (human, organisasi, dan teknologi) terhadap variabel terikat faktor EUCS (End User Computing Satisfaction). Subyek penelitian adalah operator sistem informasi primay care dengan sampel sebesar 90 klinik pratama yang ada di kabupaten kota pekanbaru yang diambil secara total sampling. Berdasarkan hasil penelitian didapat bahwa reponden yang menyatakan human cukup baik cenderung merasakan puas terhadap penggunaan $\mathrm{p}$ care yaitu sebanyak $2(100 \%)$, reponden yang menyatakan organization cukup baik cenderung merasakan puas terhadap penggunaan $\mathrm{p}$ care yaitu sebanyak $5(100 \%)$, dan reponden yang menyatakan Technologi cukup baik cenderung merasakan cukup puas terhadap penggunaan $\mathrm{p}$ care yaitu sebanyak $6(60 \%)$.
\end{abstract}

Kata kunci: human, organization, technology, EUCS, Klinik pratama

\section{Pendahuluan}

Teknologi Informasi (TI) semakin berkembang pesat pada zaman sekarang, ini terbukti dengan adanya penggunaan komputer sebagai sarana pendukung kegiatan manusia di berbagai bidang, termasuk dibidang kesehatan (Marcelino et al., 2016)

Sistem informasi kesehatan berbasis komputer telah lama dikenal dan diaplikasikan dibidang kesehatan, bahkan dilevel puskesmas telah mengenal beberapa aplikasi seperti Simpus (Sistem Informasi
Puskesmas), SP3 (Sistem Pencatatan dan Pelaporan Puskesmas), dan Primary care (P-Care) BPJS Kesehatan (Herlina \& Kemal N. Siregar, 2014).

Sejak Januari 2014 pemerintah telah memberlakukan program jaminan Kesehatan Nasional yang dikelola oleh badan berupa BPJS (Badan Pengelola Jaminan Sosial). Dalam perkembangannya, untuk memudahkan verifikasi kepesertaan, serta kebutuhan akan berjalannya sistem rujukan ke tingkat pelayanan yang lebih tinggi, BPJS meluncurkan aplikasi Primary Care atau dikenal dengan istilah P-Care. 
Seluruh klinik pratama dan pelayanan kesehatan dasar lainnya yang bekerjasama dengan BPJS diharuskan untuk menggunkan aplikasi ini.

Primary Care BPJS Kesehatan ini diaplikasikan di bagian registrasi pasien, memiliki bahan masukan, antara lain identitas pasien (nama, alamat, jenis kelamin, tanggal lahir) nomor kepesertaan, poliklinik tujuan, anamnese, pemeriksaan fisik, diagnosa, pemeriksaan penunjang sampai pemberian obatobatan. Adapun output dari aplikasi ini masih sebatas daftar nama pasien yang berkunjung, status pasien (dirujuk/tidak), hasil diagnosa (Purba. H, 2014).

Primary Care memiliki banyak manfaat diantaranya seperti dapat memberikan pelayanan yang cepat kepada peserta BPJS yang dalam hal ini disebut sebagai pasien, dimana data dari pelayanan kesehatan yang dilakukan oleh dokter yang ada di fasilitas kesehatan tingkat pertama nantinya dapat dibaca secara langsung oleh Rumah Sakit rujukan. Manfaat berikutnya adalah dengan Primary Care petugas bisa mengetahui jumlah peserta yang terdaftar, dapat mengetahui riwayat pelayanan medis masing-masing pasien, dapat mencetak rujukan, penyimpanan data bersifat elektronik dan lain-lain (Senja, 2018).

Kepuasan pengguna aplikasi Primary Care menjadi kebutuhan untuk menjamin kinerja pelaporan pelayanan ke BPJS. Untuk mengukur tingkat kepuasan aplikasi Primary Care tersebut, maka digunakanlah metode End-User Computing Satisfaction (EUCS).

Pengukuran terhadap kepuasan telah mempunyai sejarah yang panjang dalam disiplin ilmu sistem informasi. Dalam lingkup end-user computing, sejumlah studi telah dilakukan untuk mengcapture keseluruhan evaluasi di mana pengguna akhir telah menganggap penggunaan dari suatu sistem informasi (misalnya kepuasan) dan juga faktor-faktor yang membentuk kepuasan ini. (Doll et al. 1995 disitasi oleh Chin et al., 2000)

Yusof et al. $(2006,10)$ memberikan suatu kerangka baru yang dapat digunakan untuk melakukan evaluasi sistem informasi yang disebut HumanOrganizationTechnology (HOT) Fit Model. Model ini menempatkan komponen penting dalam sistem informasi yakni Manusia (Human), Organisasi (Organization) dan Teknologi (Technology). dan kesesuaian hubungan di antaranya.

Berdasarkan hasil survey pendahuluan pada tiga klinik pratama kota pekanbaru, menunjukkan bahwa masih ada permasalahan pada penggunaan sistem informasi Primary Care, diantaranya sistem yang sering eror, database peserta yang berubah. Struktur organisasi dan SOP yang belum ada juga menjadi suatu permasalahan yang ada. Oleh karena itu penulis tertarik untuk melakukan penelitian di klinik pratama kota pekanbaru dengan judul "Hubungan Human, Organisasi, Dan Teknologi Terhadap Kepuasan Penggunaan Aplikasi Primary Care Di Klikik Pratama Kota Pekanbaru”.

\section{Metode}

Jenis penelitian adalah penelitian kuantitatif bersifat cross sectional dengan obyek sistem informasi Primary Care. Variabel yang diteliti adalah variabel bebas faktor HOT (human, organisasi, dan teknologi) terhadap variabel terikat faktor EUCS (End User Computing Satisfaction). Subyek penelitian adalah operator sistem informasi primay care dengan sampel sebesar 90 klinik pratama yang ada di kabupaten kota pekanbaru yang diambil secara total sampling. Instrumen penelitian menggunakan kuesioner. Analisis data dilakukan dengan dua tahapan yaitu analisis univariat, bivariate.

\section{Hasil}

Univariat

Tabel 1 Karakteristik Responden

\begin{tabular}{llcc}
\hline $\begin{array}{c}\text { Karakteristik } \\
\text { Responden }\end{array}$ & Kategori & Jumlah & $\begin{array}{c}\text { Persentase } \\
(\%)\end{array}$ \\
\hline \multirow{3}{*}{ Umur } & $20-30$ & 59 & 80 \\
& Tahun & 31 & 20 \\
& $>30$ & & \\
& Tahun & & \\
\hline & Total & 90 & 100 \\
\hline \multirow{2}{*}{ Jenis Kelamin } & Pria & 33 & 20 \\
& Wanita & 57 & 80 \\
\hline \multirow{3}{*}{ Pendidikan } & Total & 90 & 100 \\
\hline & SMA & 44 & 40 \\
& D III & 33 & 35 \\
& S1 & 13 & 25 \\
\hline \multirow{4}{*}{ Lama Bekerja } & Total & 90 & 100 \\
\hline & $<5$ Tahun & 53 & 75 \\
& 5-10 & 29 & 15 \\
& $>10$ & 17 & 10 \\
& Tahun & & \\
\hline & Total & 90 & 100 \\
\hline
\end{tabular}


Tri Purnama Sari, Wen Via Trisna, dkk. Hubungan Human, Organisasi, Dan Teknologi Terhadap ....

Dari tabel 1 tersebut, dapat dilihat bahwa :Berdasarkan kelompok umur responden, dapat diketahui bahwa umur responden yang paling banyak adalah dibawah 30 tahun yaitu berjumlah 59 orang $(80 \%)$.

Berdasarkan jenis kelamin responden, dapat diketahui bahwa responden yang paling banyak adalah berjenis kelamin wanita yaitu berjumlah 57 orang $(80 \%)$, sedangkan berjenis kelamin pria berjumlah 2 orang $(20 \%)$.

Berdasarkan tingkat pendidikan responden terlihat bahwa tingkat pendidikan responden yang paling banyak adalah SMA yaitu berjumlah 44 orang (40\%).

Berdasarkan lama bekerja responden dapat dilihat bahwa responden yang lama bekerja $>10$ tahun (besar dari) berjumlah 17 orang (10\%), sedangkan lama bekerja $<5$ tahun (kecil dari) adalah 53 orang $(75 \%)$.

Tabel 2 Hasil Univariat Variabel Dependen Dan Independen

\begin{tabular}{|c|c|c|c|}
\hline No. & Variabel & Frekuensi & Persentase \\
\hline \multirow[t]{5}{*}{1} & Human & & \\
\hline & Cukup baik & 2 & 2.2 \\
\hline & Baik & 25 & 27.8 \\
\hline & Sangat baik & 63 & 70.0 \\
\hline & Jumlah & 90 & $100 \%$ \\
\hline \multirow[t]{5}{*}{2} & Organization & & \\
\hline & Cukup baik & 5 & 5.6 \\
\hline & Baik & 20 & 22.2 \\
\hline & Sangat baik & 65 & 72.2 \\
\hline & Jumlah & 90 & $100 \%$ \\
\hline \multirow[t]{5}{*}{3} & Technology & & \\
\hline & Cukup baik & 10 & 11.1 \\
\hline & Baik & 60 & 66.7 \\
\hline & Sangat baik & 20 & 22.2 \\
\hline & Jumlah & 90 & $100 \%$ \\
\hline \multirow[t]{5}{*}{4} & EUCS & & \\
\hline & Cukup puas & 13 & 14.4 \\
\hline & Puas & 68 & 75.6 \\
\hline & Sangat puas & 9 & 10.0 \\
\hline & Jumlah & 90 & $100 \%$ \\
\hline
\end{tabular}

Dari hasil penelitian dapat diketahui bahwa sebagian besar responden yang berjumlah 2 orang $(2,2 \%)$ menyatakan bahwa faktor Human cukup baik. berdasarkan faktor organization responden yang menyatakan cukup baik sebanyak $5(5,6 \%)$, faktor technologi responden yang menyatakan cukup baik sebanyak 10 (11,1\%), dan EUCS responden yang menyatakan cukup puas sebanyak 13 (14,4\%).

\section{Bivariat}

Tabel 3 Hubungan Human Terhadap End User Computing Satisfaction (EUCS)

\begin{tabular}{|c|c|c|c|c|c|c|c|c|c|}
\hline \multirow{3}{*}{ Human } & \multicolumn{6}{|c|}{ EUCS } & \multirow{2}{*}{\multicolumn{2}{|c|}{ Total }} & \\
\hline & \multicolumn{2}{|c|}{$\begin{array}{c}\text { Cukup } \\
\text { puas }\end{array}$} & \multicolumn{2}{|c|}{ Puas } & \multicolumn{2}{|c|}{$\begin{array}{c}\text { Sangat } \\
\text { Puas }\end{array}$} & & & Value \\
\hline & $\mathrm{N}$ & $\%$ & $\mathrm{~N}$ & $\%$ & $\mathrm{~N}$ & $\%$ & $\mathrm{~N}$ & $\%$ & \\
\hline $\begin{array}{l}\text { Cukup } \\
\text { Baik }\end{array}$ & 0 & 0 & 2 & 100 & 0 & 0 & 2 & 100 & 0,000 \\
\hline Baik & 10 & 40 & 15 & 60 & 0 & 0 & 25 & 100 & \\
\hline $\begin{array}{l}\text { Sangat } \\
\text { Baik }\end{array}$ & 3 & 4,8 & 51 & 81 & 9 & 14,3 & 63 & 100 & \\
\hline jumlah & 13 & 14,4 & 68 & 75,6 & 9 & 10 & 90 & 100 & \\
\hline
\end{tabular}

Berdasarkan Tabel 3 diketahui bahwa reponden yang menyatakan human cukup baik cenderung merasakan puas terhadap penggunaan $\mathrm{p}$ care yaitu sebanyak 2 (100\%). Hasil uji statistik dengan menggunakan uji Fisher's Exact Test, diperoleh nilai P Value 0,000 $<$ Alpa 0,05 sehingga Ho ditolak yang berarti ada hubungan yang signifikan antara Human dengan End User Computing Satisfaction (EUCS).

Tabel 4 Hubungan Organazation, Terhadap End User Computing Satisfaction (EUCS)

\begin{tabular}{|c|c|c|c|c|c|c|c|c|c|}
\hline \multirow{3}{*}{$\begin{array}{c}\text { Organi- } \\
\text { zation }\end{array}$} & \multicolumn{6}{|c|}{ EUCS } & \multirow{2}{*}{\multicolumn{2}{|c|}{ Total }} & \multirow{3}{*}{$\begin{array}{c}\mathrm{P} \\
\text { Value }\end{array}$} \\
\hline & \multicolumn{2}{|c|}{$\begin{array}{c}\text { Cukup } \\
\text { puas }\end{array}$} & \multicolumn{2}{|c|}{ Puas } & \multicolumn{2}{|c|}{$\begin{array}{l}\text { sangat } \\
\text { Puas }\end{array}$} & & & \\
\hline & $\mathrm{N}$ & $\%$ & $\mathrm{~N}$ & $\%$ & $\mathrm{~N}$ & $\%$ & $\mathrm{~N}$ & $\%$ & \\
\hline $\begin{array}{l}\text { Cukup } \\
\text { Baik }\end{array}$ & 0 & 0 & 5 & 100 & 0 & 0 & 5 & 100 & \\
\hline Baik & 8 & 40 & 12 & 60 & 0 & 0 & 20 & 100 & 0,002 \\
\hline $\begin{array}{l}\text { Sangat } \\
\text { Baik }\end{array}$ & 5 & 7,7 & 51 & 78,5 & 9 & 13,3 & 65 & 100 & \\
\hline jumlah & 13 & 14,4 & 68 & 75,6 & 9 & 10 & 90 & 100 & \\
\hline
\end{tabular}

Berdasarkan Tabel 4 diketahui bahwa reponden yang menyatakan organization cukup baik cenderung merasakan puas terhadap penggunaan $\mathrm{p}$ care yaitu sebanyak $5(100 \%)$ 
Hasil uji statistik dengan menggunakan uji Fisher's Exact Test, diperoleh nilai P Value 0,002 < Alpa 0,05 sehingga Ho ditolak yang berarti ada hubungan yang signifikan antara organization dengan End User Computing Satisfaction (EUCS).

Tabel 5 Hubungan Technologi Terhadap End User Computing Satisfaction (EUCS)

\begin{tabular}{|c|c|c|c|c|c|c|c|c|c|}
\hline \multirow{3}{*}{$\begin{array}{c}\text { Tekno- } \\
\text { logi }\end{array}$} & \multicolumn{6}{|c|}{ EUCS } & \multirow{2}{*}{\multicolumn{2}{|c|}{ Total }} & \multirow{3}{*}{$\begin{array}{c}\mathrm{P} \\
\text { Value }\end{array}$} \\
\hline & \multicolumn{2}{|c|}{$\begin{array}{c}\text { Cukup } \\
\text { puas }\end{array}$} & \multicolumn{2}{|c|}{ Puas } & \multicolumn{2}{|c|}{$\begin{array}{c}\text { Tidak } \\
\text { Puas }\end{array}$} & & & \\
\hline & $\mathrm{N}$ & $\%$ & $\mathrm{~N}$ & $\%$ & $\mathrm{~N}$ & $\%$ & $\mathrm{~N}$ & $\%$ & \\
\hline $\begin{array}{l}\text { Cukup } \\
\text { Baik }\end{array}$ & 6 & 60 & 4 & 40 & 0 & 0 & 10 & 100 & \\
\hline Baik & 7 & 11,7 & 48 & 80 & 5 & 8,3 & 60 & 100 & 0,000 \\
\hline $\begin{array}{l}\text { Sangat } \\
\text { Baik }\end{array}$ & 0 & 0 & 16 & 80 & 4 & 20 & 20 & 100 & \\
\hline jumlah & 13 & 14,4 & 68 & 75,6 & 9 & 10 & 90 & 100 & \\
\hline
\end{tabular}

Berdasarkan Tabel 5 diketahui bahwa reponden yang menyatakan Technologi cukup baik cenderung merasakan cukup puas terhadap penggunaan $\mathrm{p}$ care yaitu sebanyak $6(60 \%)$

Hasil uji statistik dengan menggunakan uji Fisher's Exact Test, diperoleh nilai P Value 0,000 < Alpa 0,05 sehingga Ho ditolak yang berarti ada hubungan yang signifikan antara technology dengan End User Computing Satisfaction (EUCS).

\section{Pembahasan}

\section{Hubungan human dengan EUCS}

Berdasarkan hasil penelitian tersebut didapatkan hasil penelitian $\mathrm{p}$ value adalah 0,000 . Hal ini menunjukkan adanya hubungan yang bermakna antara faktor Human dengan tingkat kepuasan penggunaan Primary Care di klinik pratama kota Pekanbaru Tahun 2019.

Ada beberapa komponen yang mempengaruhi faktor Human yaitu pengetahuan, sikap, dan tindakan. Menurut Notoatmodjo (2010) pengetahuan adalah segala sesuatu yang diketahui atau kepandaian yang dimiliki seseorang yang diperoleh dari pengalaman, latihan, atau melalui proses belajar. Sikap merupakan kesiapan atau kesediaan untuk bertindak, dan bukan merupakan pelaksanaan motif tertentu. Dan tindakan adalah seseorang yang mengetahui stimulus atau objek kesehatan, kemudian mengadakan penilaian atau pendapat terhadao apa yang diketahui proses selanjutnya melaksanakan atau mempraktikkan apa yang diketahui atau disikapinya (dinilai baik).

Kepuasan pengguna adalah salah satu indikator dalam mengevaluasi sistem informasi. Penelitian yang dilakukan oleh Ariaji dkk (2013) dalam jurnal Asih dan Roro (2018) menemukan bahwa antar faktor dalam kepuasan pengguna (isi, keakuratan, format, kemudahan, dan ketepatan waktu) memiliki hubungan yang kuat.

Menurut Kristyanto (2016) menyatakan bahwa faktor manusia memberikan pengaruh terhadap manfaat yang dirasakan dalam pemanfaatan sistem informasi. Hal ini dapat dilihat dari kondisi pada setiap variabelnya yaitu kondisi pada penggunaan sistem, dan kondisi pada kepuasan pengguna.

Dari hasil penelitian yang dilakukan maka peneliti berpendapat bahwa di klinik pratama kota Pekanbaru masih banyak yang cukup puas akan faktor Human yaitu 13 orang $(14,4 \%)$, hal ini dapat dilihat dari beberapa komponen Human yaitu pengetahuan, sikap, dan tindakan yang sangat mempengaruhi kepuasan pengguna dalam menggunakan aplikasi Primary Care. Untuk itu perlu adanya sosialisasi dan pelatihan untuk meningkatkan pengetahuan, sikap, dan tindakan petugas pendaftaran dalam menggunakan aplikasi Primary Care. Sosialisasi penting untuk menjamin kegiatan terlaksana dengan baik dan pelatihan juga bertujuan untuk meningkatkan skill dalam menjalankan tugas terhadap aplikasi Primary Care.

\section{Hubungan organization dengan EUCS}

Berdasarkan hasil penelitian tersebut didapatkan hasil penelitian $\mathrm{p}$ value adalah 0,002 . Hal ini menunjukkan adanya hubungan yang bermakna antara faktor organization dengan tingkat kepuasan penggunaan Primary Care di klinik pratama kota Pekanbaru Tahun 2019.

Sri Astuti, (2001) berpendapat bahwa penggunaan teknologi informasi, pemanfaatan informasi oleh individual, kelompok atau organisasi merupakan variabl inti dalam riset sistem informasi, sebab sebelum digunakan pertama terlebih dahulu dipastikan tentang penerimaan atau penolakan di gunakannya TI tersebut, hal ini berkaitan dengan perilaku yang ada pada individu/organisasi yang menggunakan teknologi komputer. 
Tri Purnama Sari, Wen Via Trisna, dkk. Hubungan Human, Organisasi, Dan Teknologi Terhadap ....

Menurut Boodnar dan Hopwood (1995), pengembangan TI memerlukan perencanaan dan implementasi yang hati-hati untuk menghindari adanya penolakan terhadap sistem yang dikembangkan, dan ini sangat berhubungan dengan perubahan prilaku secara individual dalam melaksanakan pekerjaannya. Lawrence dan Low (1993) dalam Kusnadi (2001) Nur Indriantoro (2000) Jarvenva dan Ivees (1991) memberikan sebuah contoh aspek partisipasi dan keterlibatan pengguna sebagai salah satu perwujudan dari aspek keprilakuan yang penting diperhatikan untuk menghindari penolakan (resistance) implementasi suatu sistem. Hal ini sejalan dengan pendapat Sabherwal dan Elam (1995) yang menyatakan bahwa Penerapan TI menimbulkan problematik dari berbagai faktor dan diantaranya adalah faktor prilaku. Hasil penelitian yang dilakukan oleh Guimares dan Ramanujam (1996), Lee (1986), Strassman (1985) dalam Nur Indriantoro (2000), menemukan bahwa penerapan TI dalam suatu organisasi mendorong terjadinya perubahan revolusioner terhadap prilaku individu dalam bekerja, dan dalam konteks penggunaan PC, kemungkinan seseorang mempunyai keyakinan bahwa penggunaan komputer akan memberikan manfaat bagi dirinya dan pekerjaannya (Nur Indriantoro,2000).

Dari hasil penelitian yang dilakukan maka peneliti berpendapat bahwa di klinik pratama kota Pekanbaru masih banyak yang cukup puas faktor organisasi yaitu 13 orang $(14,4 \%)$. hal ini dapat dilihat dari aspek organisasi dimana, Kepuasan Penggunap care secara tidak langsung dipengaruhi oleh kesuksesan sistem informasi/ $p$ care itu sendiri. selain itu kepemimpinan, pemantauan serta kebijakan dari pimpinan suatu organisasi juga sangat berpengaruh penting dalam penerapan dan penggunaan aplikasi $p$ care karena dengan puasnya pengguna menggunakan sistem tersebut memberikan manfaat terhadap penggunanya dan perusahaan antara lain yaitu meningkatkan kinerja individu pengguna, menambah pengetahuan pengguna, meningkatkan image klinik, kepercayaan dan loyalitas pelanggan karena semakin baiknya kualitas pelayanan yang diberikan oleh klinik pratama di kota pekanbaru.

\section{Hubungan technology dengan EUCS}

Berdasarkan hasil penelitian tersebut didapatkan hasil penelitian $\mathrm{p}$ value adalah 0,000 . Hal ini menunjukkan adanya hubungan yang bermakna antara faktor organization dengan tingkat kepuasan penggunaan Primary Care di klinik pratama kota Pekanbaru Tahun 2019.

Teknologi informasi adalah segala bentuk teknologi yang diterapkan untuk memproses dan mengirimkan informasi dalam bentuk elektronis. Komponen teknologi menilai sistem informasi dari sisi kualitas sistem, kualitas informasi, dan kualitas layanan (Musrifah, 2017).

Menurut penelitian yang dilakukan oleh Dwi dkk (2015), menyatakan bahwa kualitas sistem, kualitas informasi, dan kualitas layanan memiliki pengaruh terhadap penggunaan sistem dan kepuasan pengguna hal ini berarti semakin meningkat kualitas sistem, kualitas informasi dan kualitas layanan maka akan meningkatkan penggunaan sistem dan kepuasan pengguna.

Dari hasil penelitian yang dilakukan maka peneliti berpendapat bahwa di klinik pratama kota Pekanbaru masih banyak yang cukup puas faktor Teknologi yaitu 13 orang $(14,4 \%)$. Hal ini dapat dilihat dari aspek kualitas sistem, kualitas informasi, dan kualitas layanan yang memiliki pengaruh terhadap penggunaan sistem dan kepuasan terhadap sistem informasi Primary Care. Untuk itu perlu diperhatikan dan ditingkatkan kualitas sistem, kualitas informasi, dan kualitas layanan untuk menghasilkan kepuasan pengguna yang baik.

\section{Simpulan}

Berdasarkan hasil penelitian diketahui bahwa reponden yang menyatakan human cukup baik cenderung merasakan puas terhadap penggunaan $\mathrm{p}$ care yaitu sebanyak $2(100 \%)$, reponden yang menyatakan organization cukup baik cenderung merasakan puas terhadap penggunaan $\mathrm{p}$ care yaitu sebanyak 5 $(100 \%)$, dan reponden yang menyatakan Technologi cukup baik cenderung merasakan cukup puas terhadap penggunaan $\mathrm{p}$ care yaitu sebanyak $6(60 \%)$.

\section{Ucapan Terima Kasih}

Ucapan terima kasih diberikan oleh peneliti kepada ristekdikti yang telah mendanai penelitian ini hingga akhir. 


\section{Daftar Pustaka}

BPJS online. 2016. Mengenal P-Care BPJS Kesehatan. URL: www.bpjs-online.com. Diakses tanggal 28 Mei 2016.

Yusof, M. M., Paul, R. J., \& Stergioulas, L. K. (2006). Towards a framework for health information systems. In Proceedings of the Annual Hawaii International Conference on System Sciences (Vol. 5). [1579480] DOI: 10.1109/HICSS.2006.491

Eris, L. (n.d.). Sistem Informasi Kesehatan, SIMKES UGM. Retrieved from https://simkesugm06. wordpress.com/2006/10/03/model-evaluasisistem-informasi/

Saleh Wiharja, Kemas Rahmat; Santosa, Paulus Insap; and Cahyono, Ari, "Extending the Chin and Lee's End User Computing Satisfaction Model with the Task-Technology Fit Model" (2010). ACIS 2010 Proceedings. 75. http:// aisel.aisnet.org/acis2010/75

Doll, W. J., Raghunathan T. S., Lim, J. \& Gupta, Y. (1995). A Confirmatory Factor Analysis of the User Information System Satisfaction Instruments. Information Systems Management, 6(2), 177-188.

Hutami, camilla, (2016), Satisfaction Analysis On Tcs System Users Using End User Computing Satisfaction Methods (Case study: pt. tlk, bandung). Jurnal manajemen indonesia Vol. 16 - No. 1.

Rasman, (2012), gambaran hubungan unsur-unsur end-user computing satisfaction terhadap kepuasan pengguna sistem informasi rumah sakit umum daerah kota depok tahun 2012. Skripsi dipublikasikan. Diakses dari http://lib. ui.ac.id/file?file=digital/20318250-SYoel $\% 20$ Indra\%20Kusuma\%20Rasman.pdf

Daimunthe, Ismianti. (2016), Analisis Tingkat Kepuasan Pengguna Online Public Access Catalog (OPAC) DENGAN METODE EUCS (Studi Kasus: Perpustakaan UIN SUSKA
Riau). Jurnal Rekayasa dan Manajemen Sistem Informasi, Vol.2, No.1 e-ISSN 25028995 p-ISSN 2460-8181

Arthur., Eka, Andry., Robert., Abdurachman, Edi. (2008). Analisis Tingkat Kepuasan Pengguna Sistem Informasi Underwriting Pada PT Tugu Pratama Indonesia. Jurnal Piranti Warta, 11(1), 28-44.

Chin, W. W. And Lee, Matthew. K. O. (2000). A Proposed Model And Measurement Instrument For The Formation Of Is Satisfaction : The Case Of End-User Computing Satisfaction

Krisbiantoro, dkk. Evaluasi Keberhasilan Implementasi Sistem Informasi Dengan Pendekatan Hot Fit Model (Studi Kasus: Perpustakaan Stmik Amikom Purwokerto). Konferensi Nasional Sistem dan Informatika 2015 Stmik Stikom Bali. 2015.

Monalisa. S.,dkk (2018). Analisis Kesuksesan Penerapan Sistem Administrasi Akademik Menggunakan Human Organization Technology Fit Model. Jurnal Ilmiah Rekayasa dan Manajemen Sistem Informasi, Vol. 4, No. 1, Februari 2018, Hal. 36-41 e-ISSN 25028995, p-ISSN 2460-8181

Prasetyowati, A., Kushartanti, R. 2018. Pengaruh Faktor HOT (Human, Organisasi, Dan Teknologi) Terhadap Kepuasan Pengguna Sistem Informasi Primary Care Di Wilayah Kota Semarang. Jurnal Manajemen Informasi Kesehatan Indonesia. 6(1): 63-67.

Musrifah. 2017. Implementasi Teknologi Informasi Menggunakan Human Organization Technology (HOT) Fit Model Di Perpustakaan Perguruan Tinggi. Jurnal Ilmu Perpustakaan dan Informasi. 2(2): 222-242.

Sari, M.M., Sanjaya, G.Y., Meliala, A. 2016. Evaluasi Sistem Informasi Manajemen Rumah Sakit (Simrs) Dengan Kerangka Hot - Fit. Seminar Nasional Sistem Informasi Indonesia. 203208. 